\title{
Short communication: First detection of Panton-Valentine leukocidin- positive methicillin-resistant Staphylococcus aureus ST30 in raw milk taken from dairy cows with mastitis in South Korea
}

\author{
Abraham Fikru Mechesso, Su-Jeong Kim, Ho-Sung Park, ๑ Ji-Hyun Choi, Hyun-Ju Song, Mi Hyun Kim, \\ Suk-kyung Lim, $\odot$ Soon-Seek Yoon, $\odot$ and Dong-Chan Moon* ${ }^{*}$ \\ Bacterial Disease Division, Animal and Plant Quarantine Agency, 177 Hyeksin 8-ro, Gimcheon-si, Gyeongsangbuk-do 39660, Republic of Korea
}

\section{ABSTRACT}

We identified 199 Staphylococcus aureus isolates from quarter milk samples of 1,289 dairy cattle between 2014 and 2018 . About $66 \%$ of the isolates were resistant to at least 1 antimicrobial agent; the highest rate of resistance was to penicillin, followed by resistance to ampicillin, erythromycin, and sulfadimethoxine. We obtained 30 methicillin-resistant $S$. aureus (MRSA) strains from 6 farms in 3 provinces. The MRSA strains exhibited a significantly higher resistance rate to most of the tested antimicrobials than the oxacillin-susceptible strains. The MRSA strains represented 5 genotypes: ST72-t324SCCmec IV $(\mathrm{n}=14)$, ST30-t1752-SCCmec IV $(\mathrm{n}=8)$, ST188-t189-SCCmec NT ( $\mathrm{n}=6)$, ST188-t2284-SCCmec NT $(\mathrm{n}=1)$, and NT-NT-SCCmec IV $(\mathrm{n}=1)$. One of the ST188 MRSA strains represented a novel staphylococcal protein A (spa) type (t2284). In addition, 7 of the 8 ST30 MRSA strains were Panton-Valentine leukocidin (PVL)-positive and carried various staphylococcal enterotoxin encoding genes. This is the first report of PVL-positive ST30 MRSA-t1752-SCCmec IV from bovine mastitis in Korea. All of ST72-t324-SCCmec IV MRSA strains carried staphylococcal enterotoxin and leukotoxin encoding genes. They were also sensitive to most of the tested non- $\beta$-lactam antimicrobials. In contrast, ST188-t189 MRSA strains were resistant to multiple antimicrobials and predominantly carried the leukotoxin encoding gene. Taken together, these findings may indicate that dairy cows could be a major source for spreading MRSA strains, and contaminated milk could be a vehicle for transmission. Suitable hygienic measures should be established in dairy farms and processing plants to limit the likelihood of introducing MRSA into the food chain.

Key words: antimicrobial, bovine, milk, PantonValentine leukocidin toxin, Staphylococcus aureus

Received June 3, 2020.

Accepted August 21, 2020.

*Corresponding author: ansehdcks@korea.kr

\section{Short Communication}

Staphylococcus aureus continues to be one of the leading pathogens causing mastitis in dairy cows in Korea (Nam et al., 2011) and other countries (Kateete et al., 2013; Wang et al., 2018). It causes considerable financial losses for the global dairy industry because of reduced milk production and quality, as well as increased treatment costs for infected animals. Raw milk contaminated with staphylococcal toxins may also cause further problems along the food chain, giving rise to mild to severe life-threatening infections in humans (Wang et al., 2018).

Staphylococcus aureus is characterized by its rapid ability to develop resistance to antimicrobials. Virulent strains of methicillin-resistant S. aureus (MRSA) are increasingly being recovered from food and companion animals, livestock farms, hospitals, nursing homes, and the community (Nam et al., 2011; Pantosti, 2012). Panton-Valentine leukocidin (PVL) is an S. aureus-specific leukocytolytic toxin that interferes with immune defenses by disrupting phagocytic cell membranes and contributing to the severity of staphylococcal infections. The presence of members of this toxin family in dairy ruminants has been associated with bovine mastitis (Lo and Wang, 2011). In humans, however, it is related to severe cutaneous infections and occasionally necrotizing pneumonia that could lead to death (Nimmo, 2012).

Panton-Valentine leukocidin has been considered the main virulence determinant or a simple marker of community-associated MRSA. Community spread of PVL-positive S. aureus strains (ST8, ST30, and ST80) has been frequently shown in samples recovered from patients with skin, soft tissue, and bone infections in Korea (Lee et al., 2018; Park et al., 2019). Recently, Song et al. (2019) reported invasive sporadic cases of $S$. aureus infections that were predominantly associated with PVL-harboring ST8 and ST30 MRSA. Many authors reported the prevalence and molecular characteristics of MRSA isolated from mastitic milk in Korea before 2013 (Nam et al., 2011; Song et al., 2016). In the 
current study, we aimed to provide further information on the resistance profiles of $S$. aureus and molecular characteristics of MRSA isolated from bovine mastitis cases from 2014 to 2018.

We collected a total of 3,422 milk samples from 1,289 dairy cattle on 69 farms from 2014 to 2018 (Supplemental Table S1; https://doi.org/10.3168/jds.2020-19004). Approximately $50 \mathrm{~mL}$ of milk was collected from individual quarters of lactating cows as part of routine testing to determine the cause of mastitis. Samples were then aseptically divided into 2 sterile tubes (each containing $25 \mathrm{~mL}$ of milk) for SCC and bacteriological examination. The SCC of milk samples were determined using a Fossmatic System 4000 (Foss Electric, Hillerød, Denmark). Samples with SCC $\geq 200,000$ cells/ $\mathrm{mL}$ were subjected to bacteriological examination. Primary culture of the milk samples, identification of S. aureus using MALDI-TOF MS (bioMérieux, Marcy L'Etoile, France), and PCR confirmation of presumptive $S$. aureus and MRSA colonies were performed as described by Mason et al. (2001).

Antimicrobial susceptibility was determined with the broth microdilution method according to CLSI (2018) guidelines, using antibiotic-containing plates (CMV1AMAF; TREK Diagnostics Systems, Cleveland, OH). Ten antimicrobials were tested: ampicillin $(0.12-8 \mu \mathrm{g} / \mathrm{mL})$, ceftiofur $(0.5-4 \mu \mathrm{g} / \mathrm{mL})$, cephalothin $(2-16 \mu \mathrm{g} / \mathrm{mL})$, erythromycin $(0.25-4 \mu \mathrm{g} / \mathrm{mL})$, oxacillin $+2 \% \mathrm{NaCl}$ $(2-4 \mu \mathrm{g} / \mathrm{mL})$, penicillin $(0.12-8 \mu \mathrm{g} / \mathrm{mL})$, penicillin/ novobiocin $(1 / 2-8 / 16 \mu \mathrm{g} / \mathrm{mL})$, pirlimycin $(0.5-4 \mu \mathrm{g} /$ $\mathrm{mL})$, sulfadimethoxine $(32-256 \mu \mathrm{g} / \mathrm{mL})$, and tetracycline $(1-8 \mu \mathrm{g} / \mathrm{mL})$. The concentration range of oxacillin in the plates did not include the breakpoint $(0.5 \mu \mathrm{g} /$ $\mathrm{mL}$ ), so the agar dilution assay was performed at the oxacillin (Sigma-Aldrich, St. Louis, MO) test range of $0.0064-16 \mu \mathrm{g} / \mathrm{mL}$. Antimicrobial resistance breakpoints were determined based on CLSI (2018) guidelines and Saini et al. (2012). Staphylococcus aureus ATCC 25923 was used as a quality-control strain. Isolates demonstrating resistance to at least 3 antimicrobial subclasses were considered multidrug-resistant.

Multilocus sequence typing was performed according to Enright et al. (2000). Specific primers (Genotech, Daejeon, Korea) were used to amplify and sequence the following 7 housekeeping genes: arc $C$, aro $E, g l p F, g m k$, pta, tpi, and yqiL. Chromosomal DNA was digested with SmaI (TaKaRa, Shiga, Japan) and pulsed-field gel electrophoresis (PFGE; Bio-Rad, Hercules, CA) was conducted to determine the genetic relatedness of the isolates, according to McDougal et al. (2003). Staphylococcal cassette chromosome mec (SCCmec) typing was conducted using multiplex PCR as described by Boyle-Vavra and Daum (2007). S. aureus protein A (spa) typing was performed using the method de- scribed by Enright et al. (2000), and the spa types were assigned using the Ridom Staph Type server (Ridom GmbH, Wurzburg, Germany; www.spaserver.ridom .de). As well, a PCR assay was used to determine the presence of staphylococcal toxin genes encoding PVL, leukotoxins (LukED), exfoliatins (eta and etb), toxic shock syndrome toxin 1 (tsst1), and staphylococcal enterotoxins (sea, seb, sec, sed, see, seg, seh, seli, selj, sek, sell, sem, sen, seo, sep, seq, and ser; Yamada et al., 2005).

Among 3,422 milk samples collected in this study, $1,395(40.8 \%)$ samples had high SCC $(\geq 200,000$ cells $/$ mL; Supplemental Table S1; https://doi.org/10.3168/ jds.2020-19004). Of the samples with high SCC, we recovered 199 S. aureus isolates $(14.3 \%)$, a lower rate than found in a previous report from Korea (25\%; Song et al., 2016). The isolates exhibited resistance rates to most of the tested antimicrobials that were comparable with the findings of Moon et al. (2007) and Nam et al. (2011). However, the sulfadimethoxine (19.6\%), oxacillin $(15.1 \%)$, and pirlimycin $(12.6 \%)$ resistance rates were high compared with the above studies (Table 1 ). Although the erythromycin resistance rate decreased over time $(P<0.05)$, the overall resistance rate $(17.6 \%)$ was higher than the studies above. The penicillin resistance rate $(54.8 \%)$ was consistent with previous reports from Japan (Hata et al., 2010) and Turkey (Güler et al., 2005). However, it was higher than other reports from Japan (27\%; Yoshimura et al., 2002), Kenya (24\%; Shitandi and Sternesjö, 2004), the United States (13\%; Anderson et al., 2006), and Sweden (7\%; Bengtsson et al., 2009). The ampicillin resistance rate remained high throughout the study period, a finding consistent with those of Erskine et al. (2002) in the United States and Güler et al. (2005) in Turkey. We also identified a relatively small number of isolates that were resistant to ceftiofur, cephalothin, penicillin/novobiocin, and tetracycline. Although the rate of resistance to multiple antimicrobials decreased over time $(P<0.05)$, the overall proportion of multidrug-resistant isolates in this study (16.1\%) was higher than our previous report (Nam et al., 2011). Resistance to ampicillin, erythromycin, penicillin, and pirlimycin was the major multidrug resistance pattern (Supplemental Table S2; https: //doi.org/10.3168/jds.2020-19004). The high resistance rate of $S$. aureus isolates to these antibiotics was not difficult to explain, because these antimicrobials are commonly used in the Korean dairy industry to treat bovine mastitis (APQA, 2018).

We identified a total of $30(15.1 \%)$ MRSA strains from 6 farms in 3 provinces, 13 of which $(43.3 \%)$ were recovered in 2015 (Tables 1 and 2). The percentage of MRSA strains found in this study was in close agreement with Song et al. (2016) in Korea and Türkyllmaz 


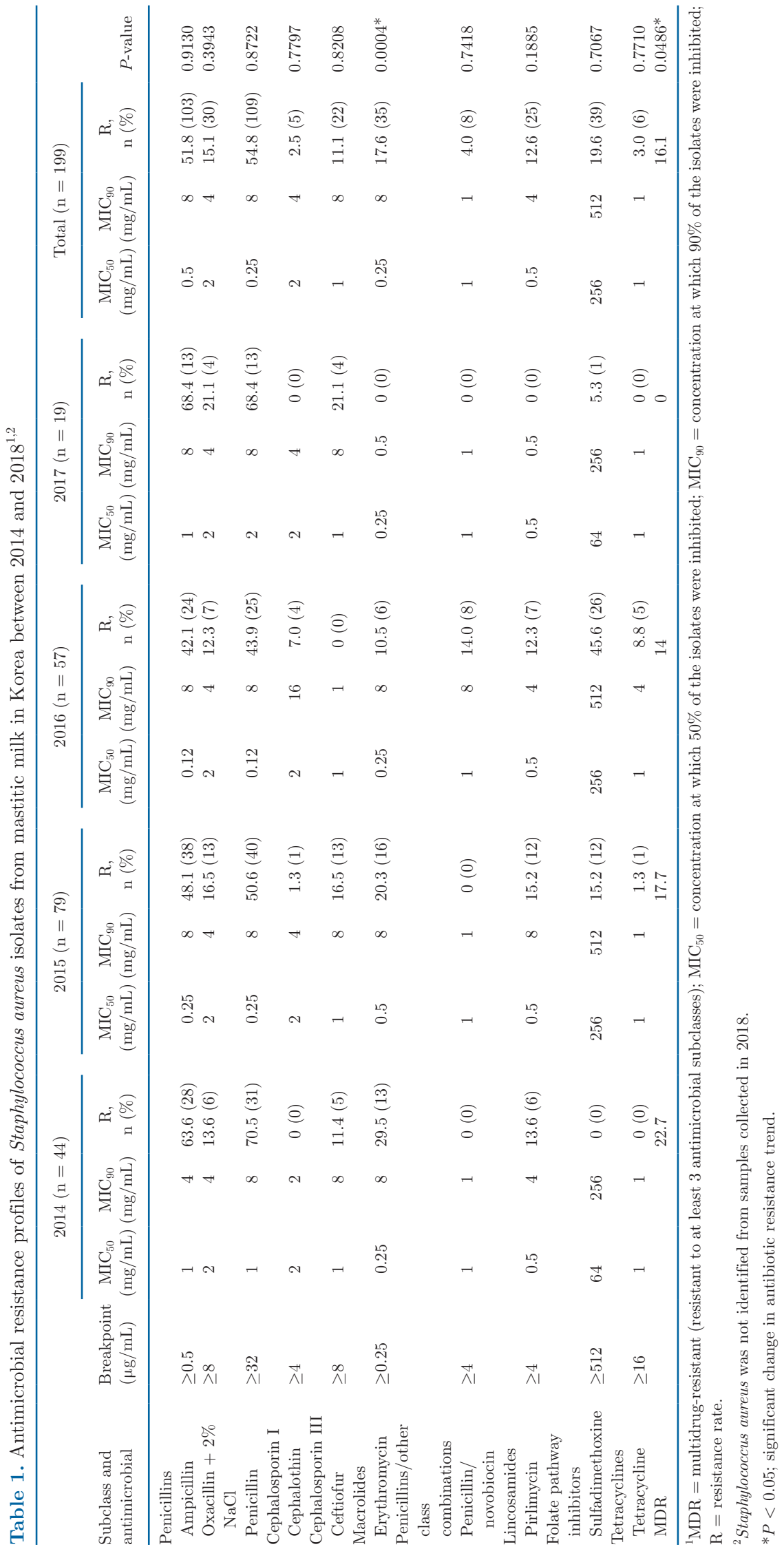


et al. (2010) in Turkey. However, it was higher than previous reports in Korea (Moon et al., 2007; Nam et al., 2011) and other countries (Bengtsson et al., 2009; Vanderhaeghen et al., 2010). Difference in sampling and detection methodology should be considered when comparing and contrasting our results with others. In the above studies, $S$. aureus isolates were identified either from milk samples with high SCC (Moon et al., 2007; Bengtsson et al., 2009; Nam et al., 2011; Song et al., 2016) or from animals with clinical mastitis (Türkyılmaz et al., 2010; Vanderhaeghen et al., 2010). As well, we observed differences in the types of growth media and PCR conditions used to identify S. aureus and MRSA strains. Further, MRSA strains were identified either after an initial screening on a medium containing various $\beta$-lactam antibiotics (Moon et al., 2007; Bengtsson et al., 2009; Türkyılmaz et al., 2010; Nam et al., 2011) or through direct detection of the mecA gene (Vanderhaeghen et al., 2010; Song et al., 2016).

Regular surveillance of MRSA susceptibility patterns is essential to provide clinicians with the most up-todate information about changes in resistance patterns. In agreement with Song et al. (2016), we found that 16 MRSA strains (53.3\%) were resistant to multiple antimicrobials (Figure 1). Except for pirlimycin and sulfadimethoxine, we observed a significantly high $(P<$ 0.001 , Student's $t$-test) antimicrobial resistance rate in MRSA strains compared with the oxacillin-susceptible strains. The resistance of MRSA to multiple antimicrobials in this study was not surprising, because MRSA strains carry SCCmec elements and additional resistance determinants (Zhang et al., 2005).

Continuous monitoring and characterization of MRSA strains in raw milk are vital to determine the evolution and dissemination of specific clones and establish an effective control program. We identified 3 major MRSA genotypes from 5 different farms. Of the 30 MRSA strains originating from 3 farms, 14 belonged to ST72-t324-SCCmec IV without the PVL-encoding gene, which has been reported to be the most common clonal type circulating in the community in Korea (Park et al., 2016; Bae et al., 2019). It has also been identified from the raw milk of dairy cows with mastitis, from cattle and pig carcasses, and from slaughterhouse workers (Nam et al., 2011; Moon et al., 2015).

All PVL-negative MRSA strains from farm $\mathrm{H}$ belonged to ST188-t189-NT. The ST188-t189 MRSA strain has been frequently identified from pigs, farmers, and hospital patients in Korea (Ko et al., 2008; Bae et al., 2019; Moon et al., 2019), but this is the first report of this strain from bovine milk in Korea. Similar to the findings of Wang et al. (2014), we found that ST188t189 MRSA was resistant to multiple antimicrobials.
As well, the only ST188 MRSA strain from farm B in Gyeongbuk province presented a novel spa type (t2284).

In this study, except for a single untypable isolate, all of the isolates from farm $\mathrm{F}$ in Gyeonggi were identified as ST30-t1752-SCCmec IV. The ST30 MRSA-SCCmec IV strain has been spreading between the community and hospitals in various Asian countries including Korea (Ko et al., 2008; Song et al., 2011; Park et al., 2019). Consistent with the findings of Williamson et al. (2013) in New Zealand and Wang et al. (2017) in Taiwan, ST30 MRSA-SCCmec IV MRSA strains were spa type t1752. We also detected PVL-encoding genes in 7 of the 8 ST30 MRSA strains. The proportion of PVL-positive $S$. aureus isolates in the current study was higher than in reports from Italy (61\%; Zecconi et al., 2006), China (42\%; Wang et al., 2015), and India (42\%; Mitra et al., 2013). Although PVL-positive ST30 has been commonly reported in patients in Korea (Lee et al., 2018; Park et al., 2019), this study is the first to report PVLpositive ST30 MRSA strains from non-human sources in Korea. The increased rate of PVL-positive MRSA in raw milk could be an additional risk factor for public health, because it is likely to be related to recurrent or chronic skin and soft tissue infections, as well as rapidly fatal pneumonia in humans (Cavalcante et al., 2015).

Analysis using PFGE revealed 6 distinct PFGE types, with identical PFGE types in each farm (Supplemental Figure S1; https://doi.org/10.3168/jds.2020-19004). The results suggest that transmission of MRSA could occur between cattle or between the milker's hand and cattle during milking. The ST72-t324-SCCmec IV MRSA strains from farms $\mathrm{A}$ and $\mathrm{C}$ in Gyeonggi presented an identical PFGE pattern (P2). These results might suggest the presence of an epidemic clone in dairy farms, or clonal spread between farms A and C.

It has been reported that MRSA strains differed in their carriage of enterotoxin and leucotoxin encoding genes. Consistent with previous reports (Song et al., 2016; Kim et al., 2020), the majority (92.9\%) of ST72 MRSA strains carried identical staphylococcal enterotoxin and leukotoxin encoding genes: seg, sei, sem, sen, seo, and LukED; only LukED was predominant in the ST188 MRSA strains. We also found that the majority of ST30-IV MRSA isolates carried sei (100\%) and LukED (87.5\%) genes. However, seg was detected in a single isolate. This was slightly different from the findings of previous researchers (Aschbacher et al., 2012; Goudarzi et al., 2018), who reported that all PVLpositive ST30-IV carried seg and sei genes. Strains of MRSA harboring the classical staphylococcal enterotoxins and leucotoxins can spread to farm personnel as well into the food chain. Recent studies (Macori et al., 2017; Adame-Gomez et al., 2018; Papadopoulos et 
Mechesso et al.: SHORT COMMUNICATION: VIRULENT STRAINS OF STAPHYLOCOCCUS AUREUS

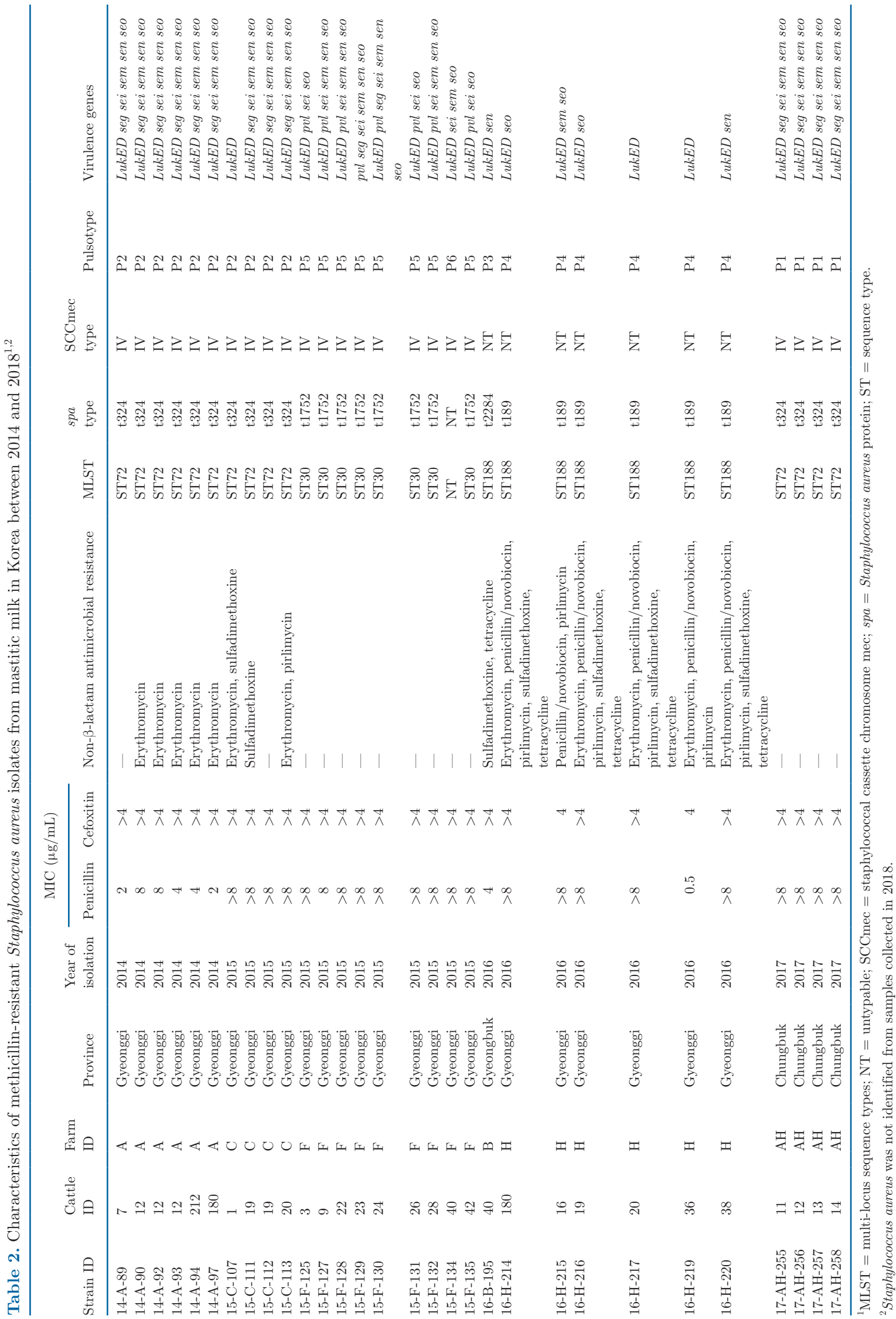




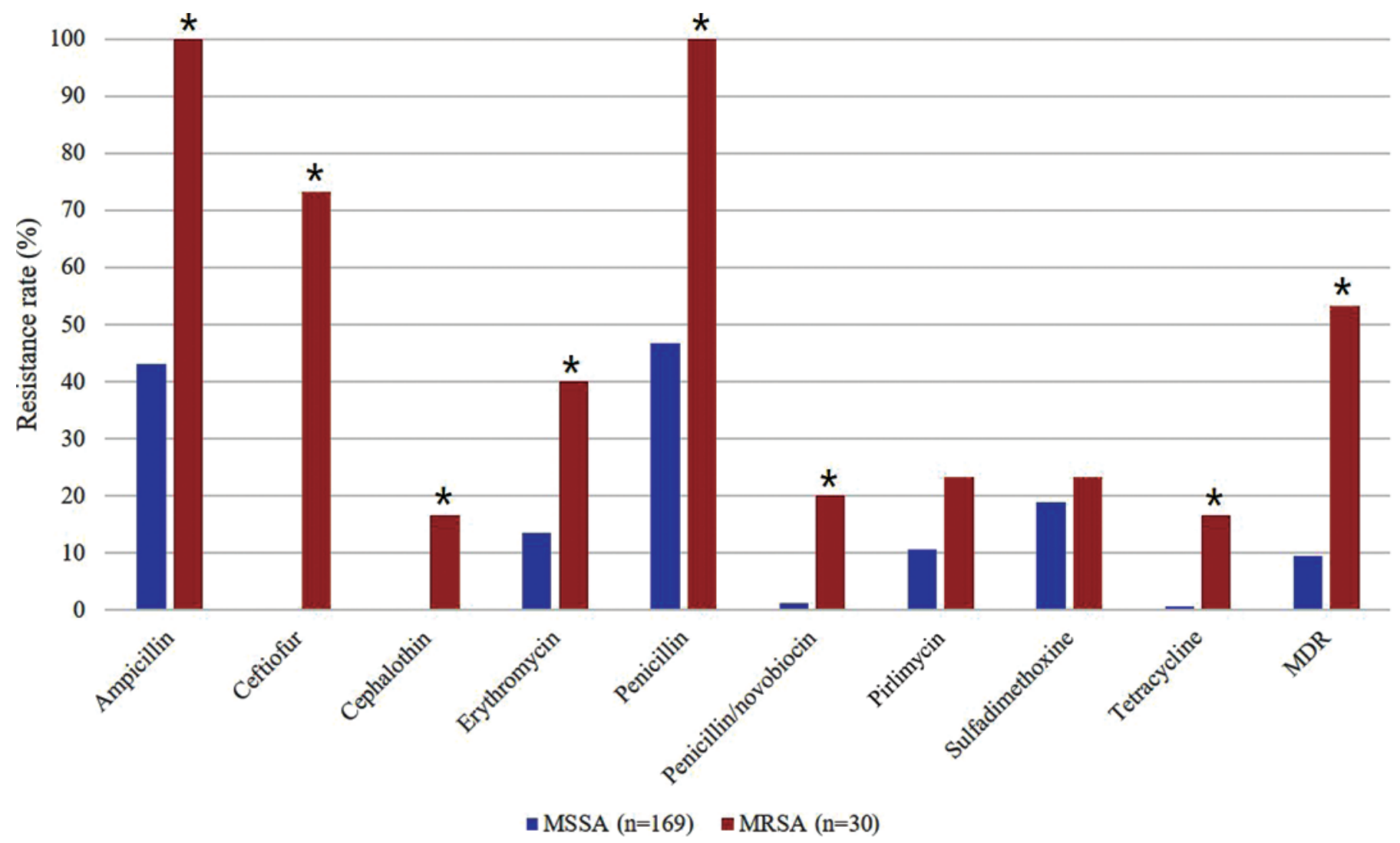

Figure 1. Antimicrobial resistance profiles of methicillin-resistant and oxacillin-susceptible Staphylococcus aureus isolated from raw milk taken from dairy cows with mastitis in Korea between 2014 and 2018. ${ }^{*} P<0.001$; significant compared with the resistance rate in MSSA. MDR $=$ multidrug-resistant; MRSA = methicillin-resistant Staphylococcus aureus; MSSA, oxacillin-susceptible Staphylococcus aureus.

al., 2019) revealed that MRSA isolated from the dairy chain, dairy products, and dairy farm personnel were enterotoxigenic and capable of causing food-related illnesses (Jones et al., 2002; Kerouanton et al., 2007).

Our results indicate a rise in the prevalence of MRSA in bovine milk in Korea. We identified new genotypes related to community-acquired MRSA strains (PVLpositive ST30-t 1752-SCCmec type IV MRSA and PVL-negative ST188-t189 MRSA) from raw milk taken from dairy cows with mastitis in Korea. Dairy farms could be major sources for spreading toxigenic and virulent MRSA strains, and contaminated milk could be a vehicle for transmission through the food chain. Inadequate hygiene (farm, dairy cattle, and farm personnel), as well as insufficient cleaning and disinfection of milking equipment, are among the most common contributing factors for the persistence and spread of infectious agents that cause mastitis. Therefore, this study supports the use of suitable hygienic measures to limit the likelihood of introducing MRSA into the food chain. In addition to the inspection of animals, regular inspection of personnel working on dairy farms should be considered. As well, further studies are needed to ex- plore the epidemiological relationship between human and animal MRSA isolates.

\section{ACKNOWLEDGMENTS}

This work was supported by a grant from the Animal and Plant Quarantine Agency, Ministry of Agriculture, Food, and Rural Affairs, Korea (N-1543081-2017-2401). The authors have not stated any conflicts of interest.

\section{REFERENCES}

Adame-Gomez, R., J. Toribio-Jimenez, A. Vences-Velazquez, E. Rodríguez-Bataz, M.C. Santiago Dionisio, and A. Ramirez-Peralta. 2018. Methicillin-resistant Staphylococcus aureus (MRSA) in artisanal cheeses in México. Int. J. Microbiol. 2018:876000357.

Anderson, K. L., R. L. Lyman, S. M. Bodeis-Jones, and D. G. White. 2006. Genetic diversity and antimicrobial susceptibility profiles among mastitis-causing Staphylococcus aureus isolated from bovine milk samples. Am. J. Vet. Res. 67:1185-1191. https://doi.org/10 .2460 /ajvr.67.7.1185.

APQA (Animal and Plant Quarantine Agency). 2018. Korean Veterinary Antimicrobial Resistance 360 Monitoring System. APQA Gimcheon, Korea. 
Aschbacher, R., B. Pichon, G. Spoladore, E. Pagani, P. Innocenti, L. Moroder, M. Ganner, R. Hill, R. Pike, O. Ganthaler, L. Pagani, C. Larcher, and A. Kearns. 2012. High clonal heterogeneity of Panton-Valentine leukocidin-positive methicillin-resistant Staphylococcus aureus strains from skin and soft-tissue infections in the province of Bolzano, Northern Italy. Int. J. Antimicrob. Agents 39:522-525. https://doi.org/10.1016/j.ijantimicag.2012.02.004.

Bae, E., C. K. Kim, J. H. Jang, H. Sung, Y. M. Choi, and M. N. Kim. 2019. Impact of community-onset methicillin-resistant Staphylococcus aureus on Staphylococcus aureus bacteremia in a central Korea veterans health service hospital. Ann. Lab. Med. 39:158-166. https://doi.org/10.3343/alm.2019.39.2.158.

Bengtsson, B., H. E. Unnerstad, T. Ekman, K. Artursson, M. NilssonÖst, and K. P. Waller. 2009. Antimicrobial susceptibility of udder pathogens from cases of acute clinical mastitis in dairy cows. Vet. Microbiol. 136:142-149. https://doi.org/10.1016/j.vetmic.2008.10 .024 .

Boyle-Vavra, S., and R. S. Daum. 2007. Community-acquired methicillin-resistant Staphylococcus aureus: The role of Panton-Valentine leukocidin. Lab. Invest. 87:3-9. https://doi.org/10.1038/labinvest .3700501

Cavalcante, F. S., E. D. Abad, Y. C. Lyra, S. B. Saintive, M. Ribeiro, D. C. Ferreira, and K. R. N. dos Santos. 2015. High prevalence of methicillin resistance and PVL genes among Staphylococcus aureus isolates from the nares and skin lesions of pediatric patients with atopic dermatitis. Braz. J. Med. Biol. Res. 48:588-594. https://doi .org/10.1590/1414-431x20154221.

CLSI (Clinical and Laboratory Standards Institute). 2018. Performance Standards for Antimicrobial Susceptibility Testing. 20th Informational Supplement. CLSI document M100. CLSI, Wayne, PA.

Enright, M. C., N. P. J. Day, C. E. Davies, S. J. Peacock, and B. G. Spratt. 2000. Multilocus sequence typing for characterization of methicillin-resistant and methicillin-susceptible clones of Staphylococcus aureus. J. Clin. Microbiol. 38:1008-1015. https://doi.org/10 .1128 /JCM.38.3.1008-1015.2000.

Erskine, R. J., R. D. Walker, C. A. Bolin, P. C. Bartlett, and D. G. White. 2002. Trends in antibacterial susceptibility of mastitis pathogens during a seven-year period. J. Dairy Sci. 85:1111-1118. https://doi.org/10.3168/jds.S0022-0302(02)74172-6.

Goudarzi, M., M. Navidinia, E. Beiranvand, and H. Goudarzi. 2018. Phenotypic and molecular characterization of methicillin-resistant Staphylococcus aureus clones carrying the Panton-Valentine leukocidin genes disseminating in Iranian hospitals. Microb. Drug Resist. 24:1543-1551. https://doi.org/10.1089/mdr.2018.0033.

Güler, L., Ü. Ok, K. Gündüz, Y. Gülcü, and H. H. Hadimli. 2005. Antimicrobial susceptibility and coagulase gene typing of Staphylococcus aureus isolated from bovine clinical mastitis cases in Turkey. J. Dairy Sci. 88:3149-3154. https://doi.org/10.3168/jds.S0022 -0302(05)72998-2.

Hata, E., K. Katsuda, H. Kobayashi, I. Uchida, K. Tanaka, and M. Eguchi. 2010. Genetic variation among Staphylococcus aureus strains from bovine milk and their relevance to methicillin-resistant isolates from humans. J. Clin. Microbiol. 48:2130-2139. https: //doi.org/10.1128/JCM.01940-09.

Jones, T. F., M. E. Kellum, S. S. Porter, M. Bell, and W. Schaffner. 2002. An outbreak of community-acquired foodborne illness caused by methicillin-resistant Staphylococcus aureus. Emerg. Infect. Dis. 8:82-84. https://doi.org/10.3201/eid0801.010174.

Kateete, D. P., U. Kabugo, H. Baluku, L. Nyakarahuka, S. Kyobe, M. Okee, C. F. Najjuka, and M. L. Joloba. 2013. Prevalence and antimicrobial susceptibility patterns of bacteria from milkmen and cows with clinical mastitis in and around Kampala, Uganda. PLoS One 8:e63413. https://doi.org/10.1371/journal.pone.0063413.

Kerouanton, A., J.A. Hennekinne, C. Letertre, L. Petit, O. Chesneau, A. Brisabosi, and M.L. De Buyser. 2007. Characterization of Staphylococcus aureus strains associated with food poisoning outbreaks in France. Int. J. Food Microbiol. 115:369-375.

Kim, H. J., Q. Choi, G. C. Kwon, and S. H. Koo. 2020. Molecular epidemiology and virulence factors of methicillin-resistant Staphy- lococcus aureus isolated from patients with bacteremia. J. Clin. Lab. Anal. 34:e23077.

Ko, K. S., J. Y. Lee, J. Y. Baek, K. R. Peck, J. Y. Rhee, K. T. Kwon, S. T. Heo, K. M. Ahn, and J. H. Song. 2008. Characterization of Staphylococcus aureus nasal carriage from children attending an outpatient clinic in Seoul, Korea. Microb. Drug Resist. 14:37-44. https://doi.org/10.1089/mdr.2008.0776.

Lee, J. Y., J. Y. Park, I. K. Bae, S. Jeong, J. H. Park, and S. Jin. 2018. Recurrent familial furunculosis associated with Panton-Valentine leukocidin-positive methicillin-susceptible Staphylococcus aureus ST1. Pediatr. Infect. Vaccine 25:107-112. https://doi.org/ 10.14776/piv.2018.25.e6.

Lo, W. T., and C. C. Wang. 2011. Panton-Valentine leukocidin in the pathogenesis of community-associated methicillin-resistant Staphylococcus aureus infection. Pediatr. Neonatol. 52:59-65. https:// doi.org/10.1016/j.pedneo.2011.02.008.

Macori, G., G. Giacinti, A. Bellio, S. Gallina, D. Bianchi, D. Sagrafoli, N. Marri, G. Giangolini, S. Amatiste, and L. Decastelli. 2017. Molecular epidemiology of methicillin-resistant and methicillinsusceptible Staphylococcus aureus in the ovine dairy chain and in farm-related humans. Toxins (Basel) 9:161. https://doi.org/10 $.3390 /$ toxins 9050161 .

Mason, W. J., J. S. Blevins, K. Beenken, N. Wibowo, N. Ojha, and M. S. Smeltzer. 2001. Multiplex PCR protocol for the diagnosis of staphylococcal infection. J. Clin. Microbiol. 39:3332-3338. https:/ /doi.org/10.1128/JCM.39.9.3332-3338.2001.

McDougal, L. K., C. D. Steward, G. E. Killgore, J. M. Chaitram, S. K. McAllister, and F. C. Tenover. 2003. Pulsed-field gel electrophoresis typing of oxacillin-resistant Staphylococcus aureus isolates from the United States: Establishing a national database. J. Clin. Microbiol. 41:5113-5120. https://doi.org/10.1128/JCM.41.11.5113 $-5120.2003$.

Mitra, S. D., D. Velu, M. Bhuvana, N. Krithiga, A. Banerjee, R. Shome, H. Rahman, S. K. Ghosh, and B. R. Shome. 2013. Staphylococcus aureus spa type t267, clonal ancestor of bovine subclinical mastitis in India. J. Appl. Microbiol. 114:1604-1615. https://doi .org/10.1111/jam.12186.

Moon, D. C., S. K. Jeong, B. H. Hyun, and S. K. Lim. 2019. Prevalence and characteristics of methicillin-resistant Staphylococcus aureus isolates in pigs and pig farmers in Korea. Foodborne Pathog. Dis. 16:256-261. https://doi.org/10.1089/fpd.2018.2509.

Moon, D. C., M. D. Tamang, H. M. Nam, J. H. Jeong, G. C. Jang, S. C. Jung, Y. H. Park, and S. K. Lim. 2015. Identification of livestock-associated methicillin-resistant Staphylococcus aureus isolates in Korea and molecular comparison between isolates from animal carcasses and slaughterhouse workers. Foodborne Pathog. Dis. 12:327-334. https://doi.org/10.1089/fpd.2014.1868.

Moon, J. S., A. R. Lee, H. M. Kang, E. S. Lee, M. N. Kim, Y. H. Paik, Y. H. Park, Y. S. Joo, and H. C. Koo. 2007. Phenotypic and genetic antibiogram of methicillin-resistant staphylococci isolated from bovine mastitis in Korea. J. Dairy Sci. 90:1176-1185. https:/ /doi.org/10.3168/jds.S0022-0302(07)71604-1.

Nam, H. M., A. L. Lee, S. C. Jung, M. N. Kim, G. C. Jang, S. H. Wee, and S. K. Lim. 2011. Antimicrobial susceptibility of Staphylococcus aureus and characterization of methicillin-resistant Staphylococcus aureus isolated from bovine mastitis in Korea. Foodborne Pathog. Dis. 8:231-238. https://doi.org/10.1089/fpd.2010.0661.

Nimmo, G. R. 2012. USA300 abroad: Global spread of a virulent strain of community-associated methicillin-resistant Staphylococcus aureus. Clin. Microbiol. Infect. 18:725-734. https://doi.org/10.1111/ j.1469-0691.2012.03822.x.

Pantosti, A. 2012. Methicillin-resistant Staphylococcus aureus associated with animals and its relevance to human health. Front. Microbiol. 3:127. https://doi.org/10.3389/fmicb.2012.00127.

Papadopoulos, P., A. S. Angelidis, T. Papadopoulos, C. Kotzamanidis, A. Zdragas, A. Papa, G. Filioussis, and D. Sergelidis. 2019. Staphylococcus aureus and methicillin-resistant S. aureus (MRSA) in bulk tank milk, livestock and dairy-farm personnel in northcentral and north-eastern Greece: Prevalence, characterization and genetic relatedness. Food Microbiol. 84:103249. https://doi.org/10 .1016/j.fm.2019.103249. 
Park, S. G., H. S. Lee, J. Y. Park, and H. Lee. 2019. Molecular epidemiology of Staphylococcus aureus in skin and soft tissue infections and bone and joint infections in Korean children. J. Korean Med. Sci. 34:e315. https://doi.org/10.3346/jkms.2019.34.e315.

Park, S. Y., D. R. Chung, J. R. Yoo, J. R. Baek, S. H. Kim, Y. E. Ha, C. I. Kang, K. R. Peck, N. Y. Lee, and J. H. Song. 2016. Sequence type 72 community-associated methicillin-resistant Staphylococcus aureus emerged as a predominant clone of nasal colonization in newly admitted patients. J. Hosp. Infect. 93:386-389. https://doi .org/10.1016/j.jhin.2015.12.008.

Saini, V., J. T. McClure, D. Léger, G. P. Keefe, D. T. Scholl, D. W. Morck, and H. W. Barkema. 2012. Antimicrobial resistance profiles of common mastitis pathogens on Canadian dairy farms. J. Dairy Sci. 95:4319-4332. https://doi.org/10.3168/jds.2012-5373.

Shitandi, A., and A. Sternesjö. 2004. Prevalence of multi-drug resistant Staphylococcus aureus in milk from large- and small-scale producers in Kenya. J. Dairy Sci. 87:4145-4149. https://doi.org/10 .3168/jds.S0022-0302(04)73557-2.

Song, J. H., P. R. Hsueh, D. R. Chung, K. S. Ko, C. I. Kang, K. R. Peck, J. S. Yeom, S. W. Kim, H. H. Chang, Y. S. Kim, S. I. Jung, J. S. Son, T. M. So, M. K. Lalitha, Y. Yang, S. G. Huang, H. Wang, Q. Lu, C. C. Carlos, J. A. Perera, C. H. Chiu, J. W. Liu, A. Chongthaleong, V. Thamlikitkul, and P. H. Van., on behalf of the ANSORP Study Group. 2011. Spread of methicillin-resistant Staphylococcus aureus between the community and the hospitals in Asian countries: An ANSORP study. J. Antimicrob. Chemother. 66:1061-1069. https://doi.org/10.1093/jac/dkr024.

Song, J. W., S. J. Yang, S. Shin, K. S. Seo, Y. H. Park, and K. T. Park. 2016. Genotypic and phenotypic characterization of methicillin-resistant Staphylococcus aureus isolated from bovine mastitic milk in Korea. J. Food Prot. 79:1725-1732. https://doi.org/10 .4315/0362-028X.JFP-16-067.

Song, K. H., E. S. Kim, K. H. Park, H. J. Choi, K. H. Kim, S. Lee, J. H. Hwang, E. J. Choo, Y. Park, E. J. Lee, Y. K. Kim, M. H. Jeon, C. Moon, J. H. Hwang, J. S. Park, K. U. Park, P. G. Choe, J. H. Bang, M. Oh, and H. B. Kim., and Korea Infectious Diseases (KIND) Study Group. 2019. Clinical and molecular characterization of Panton-Valentine leukocidin-positive invasive Staphylococcus aureus infections in Korea. Microb. Drug Resist. 25:450-456. https://doi.org/10.1089/mdr.2018.0238.

Türkyllmaz, S., S. Tekbiyik, E. Oryasin, and B. Bozdogan. 2010. Molecular epidemiology and antimicrobial resistance mechanisms of methicillin-resistant Staphylococcus aureus isolated from bovine milk. Zoonoses Public Health 57:197-203. https://doi.org/10 .1111/j.1863-2378.2009.01257.x.

Vanderhaeghen, W., T. Cerpentier, C. Adriaensen, J. Vicca, K. Hermans, and P. Butaye. 2010. Methicillin-resistant Staphylococcus aureus (MRSA) ST398 associated with clinical and subclinical mastitis in Belgian cows. Vet. Microbiol. 144:166-171. https://doi .org/10.1016/j.vetmic.2009.12.044.

Wang, D., Z. Wang, Z. Yan, J. Wu, T. Ali, J. Li, Y. Lv, and B. Han. 2015. Bovine mastitis Staphylococcus aureus: Antibiotic susceptibility profile, resistance genes and molecular typing of methicillin- resistant and methicillin-sensitive strains in China. Infect. Genet. Evol. 31:9-16. https://doi.org/10.1016/j.meegid.2014.12.039.

Wang, H. K., C. Y. Huang, and Y. C. Huang. 2017. Clinical features and molecular characteristics of childhood community-associated methicillin-resistant Staphylococcus aureus infection in a medical center in northern Taiwan, 2012. BMC Infect. Dis. 17:470. https:/ /doi.org/10.1186/s12879-017-2560-0.

Wang, W., X. Lin, T. Jiang, Z. Peng, J. Xu, L. Yi, F. Li, S. Fanning, and Z. Baloch. 2018. Prevalence and characterization of Staphylococcus aureus cultured from raw milk taken from dairy cows with mastitis in Beijing, China. Front. Microbiol. 9:1123. https://doi .org/10.3389/fmicb.2018.01123.

Wang, X., G. Li, X. Xia, B. Yang, M. Xi, and J. Meng. 2014. Antimicrobial susceptibility and molecular typing of methicillin-resistant Staphylococcus aureus in retail foods in Shaanxi, China. Foodborne Pathog. Dis. 11:281-286. https://doi.org/10.1089/fpd.2013.1643.

Williamson, D. A., S. A. Roberts, S. R. Ritchie, G. W. Coombs, J. D. Fraser, and H. Heffernan. 2013. Clinical and molecular epidemiology of methicillin-resistant Staphylococcus aureus in New Zealand: Rapid emergence of sequence Type 5 (ST5)-SCCmec-IV as the dominant community-associated MRSA clone. PLoS One 8:e62020. https://doi.org/10.1371/journal.pone.0062020.

Yamada, T., N. Tochimaru, S. Nakasuji, E. Hata, H. Kobayashi, M. Eguchi, J. Kaneko, Y. Kamio, T. Kaidoh, and S. Takeuchi. 2005 Leukotoxin family genes in Staphylococcus aureus isolated from domestic animals and prevalence of lukM-lukF-PV genes by bacteriophages in bovine isolates. Vet. Microbiol. 110:97-103. https:/ /doi.org/10.1016/j.vetmic.2005.07.006.

Yoshimura, H., M. Ishimaru, and A. Kojima. 2002. Minimum inhibitory concentrations of 20 antimicrobial agents against Staphylococcus aureus isolated from bovine intramammary infections in Japan. J. Vet. Med. B Infect. Dis. Vet. Public Health 49:457-460. https:// doi.org/10.1046/j.1439-0450.2002.t01-1-00593.x.

Zecconi, A., L. Cesaris, E. Liandris, V. Daprà, and R. Piccinini. 2006. Role of several Staphylococcus aureus virulence factors on the inflammatory response in bovine mammary gland. Microb. Pathog. 40:177-183. https://doi.org/10.1016/j.micpath.2006.01.001.

Zhang, K., J. A. McClure, S. Elsayed, T. Louie, and J. M. Conly. 2005. Novel multiplex PCR assay for characterization and concomitant subtyping of staphylococcal cassette chromosome mec types I to $\mathrm{V}$ in methicillin-resistant Staphylococcus aureus. J. Clin. Microbiol. 43:5026-5033. https://doi.org/10.1128/JCM.43.10.5026-5033 .2005 .

\section{ORCIDS}

Ho-Sung Park @ https://orcid.org/0000-0003-1719-6233 Suk-kyung Lim (i) https://orcid.org/0000-0002-7549-9411 Soon-Seek Yoon @ https://orcid.org/0000-0003-0908-8785 Dong-Chan Moon @ https://orcid.org/0000-0003-1244-201X 